\title{
Soil bio-engineering experiences in river works using wire mesh products
}

\author{
M. Vicari ${ }^{1} \&$ D. Crowther ${ }^{2}$ \\ ${ }^{1}$ Officine Maccaferri S.p.A., Zola Predosa, Italy \\ ${ }^{2}$ Maccaferri Ltd, Oxford, UK
}

\begin{abstract}
The development of sound engineering practices combined with aesthetically pleasing and environmentally enhancing solutions requires the designers to understand how to design using "living" and "inert" materials together by best combining both types of materials. The incorporation of vegetation through the use of soil bioengineering techniques improves the surface stability through the vegetative rooting system, however it is essential that the materials provide adequate strength and resistance during the initial stage of recovery of the project, as the vegetation will grow stronger over time. The challenge for the most appropriate choice is to identify a system capable of providing the required shear resistance and to be able to incorporate the most appropriate soil bioengineering treatment. Double twist steel wire products have shown an extraordinary capability for regeneration of the natural environment, since gabions and mattresses are filled with stones, soil and roots which eventually provide favourable developmental conditions. At the same time vegetation uses these structures as shelter during the initial growth phase, thus allowing these solutions to provide adequate structural and hydraulic performance even when plants are not fully developed yet. Apart from the integration aspects, a recent study has demonstrated how the use of gabions and Reno mattresses is a solution which reduces the impact on climate change, having a lower carbon footprint than equivalent traditional engineering solutions in terms of $\mathrm{CO}_{2}$ emissions. The paper presents a series of technical solutions realised in different environmental conditions to highlight the new design approach entailing river protection works and soil stabilisation.

Keywords: double twist steel wire, bank protection, vegetated gabions, carbon footprint.
\end{abstract}




\section{Introduction}

The issue of protecting river banks in natural and altered streams has always been historically a "domain" of the engineering profession (hydrologic, hydraulic and geotechnical), the purpose of which is to interpret the statistical data and provide safe and reliable designed solutions at given peak flood occurrences. In more recent times, the approach to the design of bank stabilization from the engineering perspective has profoundly changed. Today the environmental sensitivity has become a major part of the decision making process. The techniques used to protect stream banks from erosion range from simple re-vegetation, to massive retaining structures such as concrete, gabion, or mechanically stabilized wall systems. However, there are several factors contributing to the choice, many of which are directly dependent upon geotechnical, hydraulic, or environmental aspects, in relationship to the value of the land and the water. In a more modern and natural approach, in fact, the development of sound engineering practices combined with aesthetically pleasing and environmentally enhancing solutions requires the community to understand and learn how to design using both "living" and "inert" materials together. The true challenge is to combine the best of both types of materials, to be able to predict how the newly restored environment will evolve and how this will eventually improve the stability of the bank as well. The most appropriate solution will be that defined by the Minimum Energy Level: this is commonly defined as the minimum amount of intervention on the environment, which is required to solve the problem [1]. It is illustrated in Figure 1 and ranges from the lowest level of no intervention through to the highest energy level, which may necessitate the construction of a massive retaining structure, or a similar type of intervention.

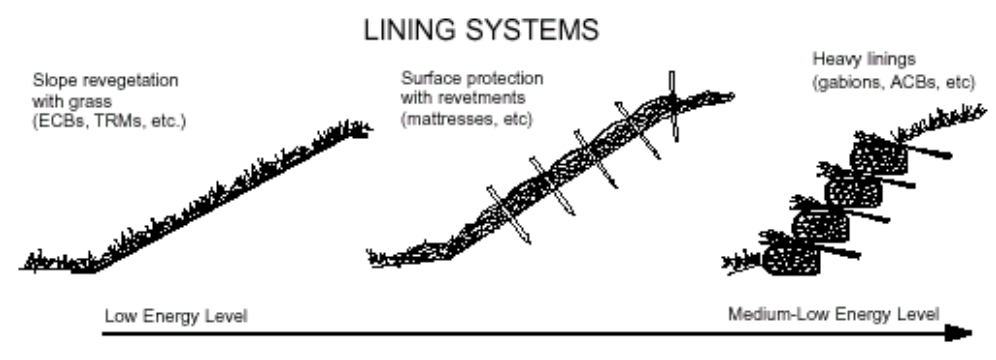

WALL SYSTEMS

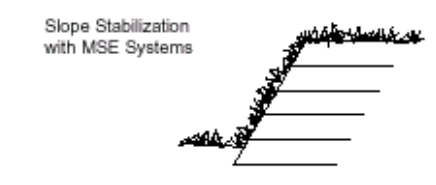

Medium-High Energy Level

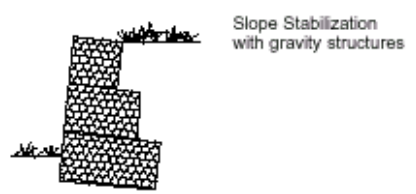

High energy level

Figure 1: The minimum energy level concept. 


\section{Carbon footprint of wire mesh products vs. traditional solutions}

Reno mattresses and gabions are environmentally friendly products: their blending into the environment is rapid and pleasing; the voids in the rockfill become progressively filled with silt, promoting vegetation growth which is essential to the preservation and maintenance of the ecological balance of the surrounding environment. Apart from the integration aspects, a recent study [2] demonstrates how the use of gabions and mattresses is a valid solution to reduce the impact on climate change, having a lower carbon footprint than equivalent traditional engineering solutions such as concrete walls or riprap revetments. A comparison has been made between two different solutions for real executed works:

- Bank protection. The equivalent solutions (Figure 2) are a Reno mattress $30 \mathrm{~cm}$ thick filled in with local river stones $(\mathrm{d}=70-100 \mathrm{~mm})$ and a rip-rap protection $1 \mathrm{~m}$ thick $(\mathrm{d}=500-700 \mathrm{~mm})$.

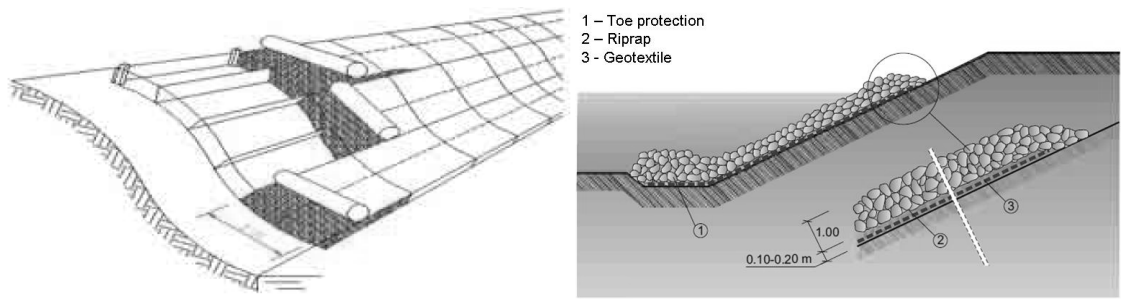

Figure 2: The bank protections analysed for the carbon footprint comparison.

- Retaining structures. The equivalent solutions (Figure 3) for an $8 \mathrm{~m}$ high retaining structure are a gabion and a traditional cast-in-place concrete $\left(\mathrm{R}_{\mathrm{ck}} 45\right)$ wall.

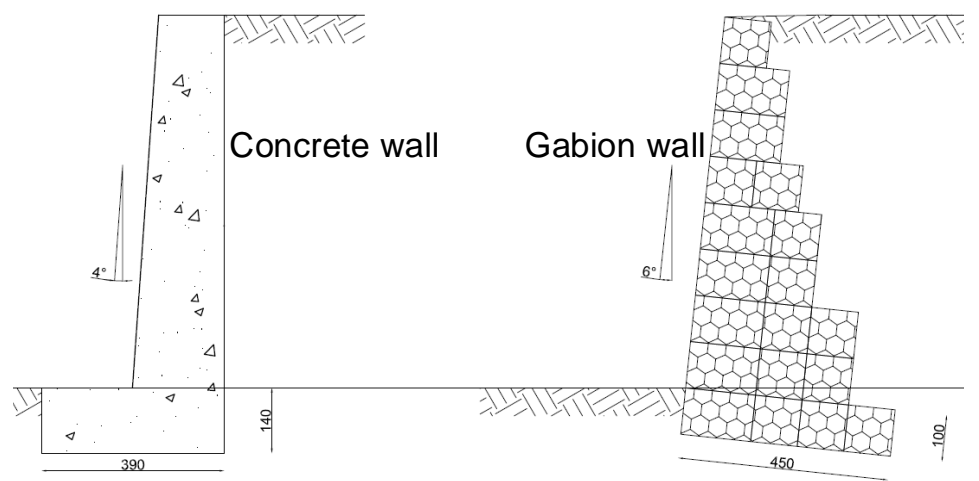

Figure 3: The retaining structures analysed for the carbon footprint comparison. 
Greenhouse gas removals have not been considered for the moment, even if gabions and mattresses allow a fast regeneration of vegetation in the areas associated with the consolidation works, which would not happen with other construction techniques. The analysis considered the entire cycle of the final structure:

- $\quad$ Production of the base materials

- Transport to the job site

- Installation procedures and equipment

Resulting emission factors are calculated in tons of $\mathrm{CO}_{2}$ per square meter surface of the solution (revetment or wall): those made with double twist wire mesh products are sensitively better in terms of emissions and carbon footprint with respect to the traditional ones (Figure 4).
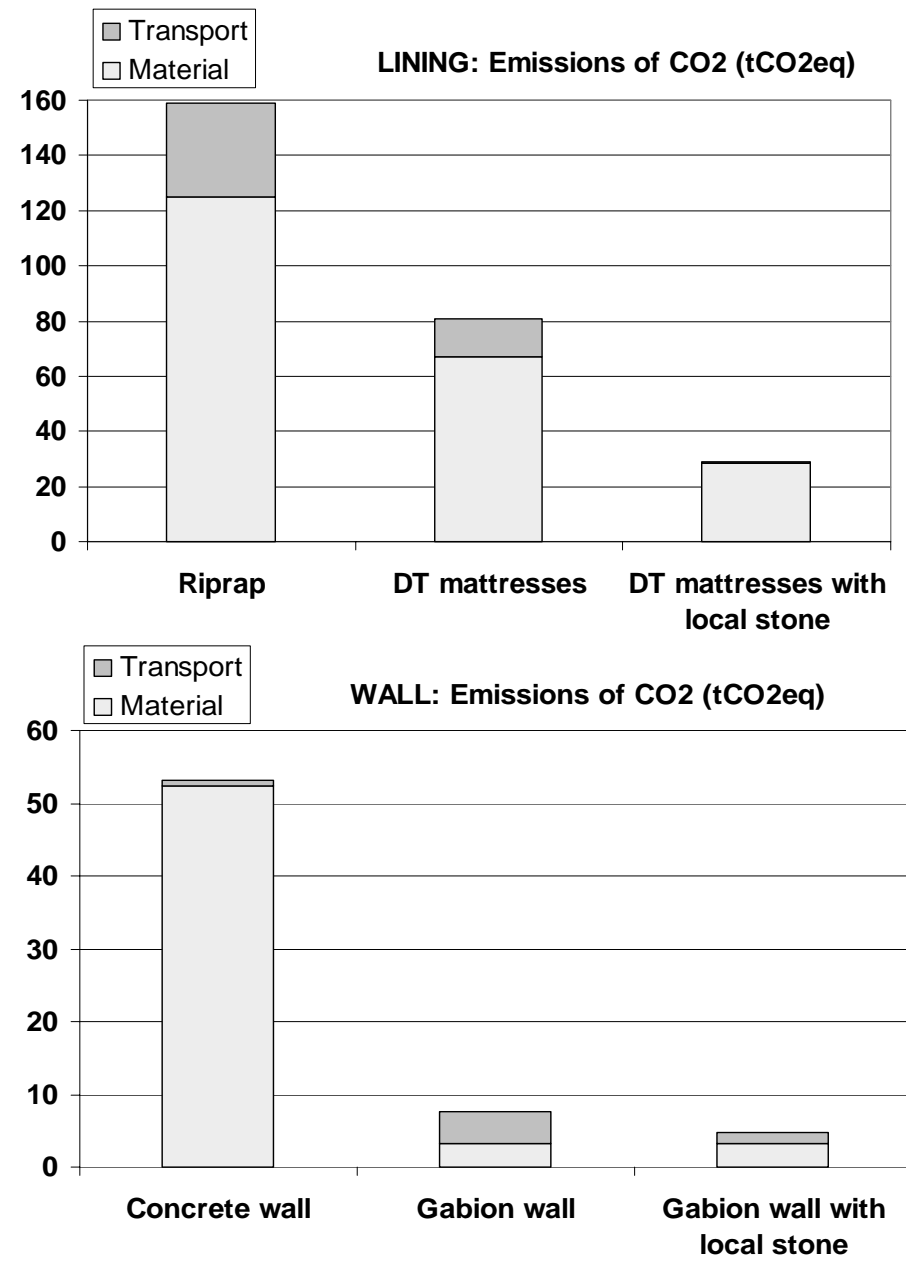

Figure 4: $\quad \mathrm{CO}_{2}$ emissions for mattresses (above) and gabions (below) vs. traditional solutions. 
For revetments, Reno mattresses are characterized by an emission of 15 $\mathrm{tCO}_{2} / \mathrm{m}^{2}$, approximately half the quantity of the $29 \mathrm{tCO}_{2} / \mathrm{m}^{2}$ released with the traditional solution (riprap). When using locally available stones (i.e. within 100 $\mathrm{km}$ from the jobsite, which is commonly the case due to the small $\mathrm{D}_{50}$ required for the filling) the carbon footprint for mattresses drops to $5.4 \mathrm{tCO}_{2} / \mathrm{m}^{2}$ only. For walls, the gabion solution is characterized by an emission of $95 \mathrm{tCO}_{2} / \mathrm{m}^{2}$ instead of the $665 \mathrm{tCO}_{2} / \mathrm{m}^{2}$ released with the concrete wall solution. When using locally available stones the carbon footprint for gabion walls drops to $58 \mathrm{tCO} / \mathrm{m}^{2}$ only.

\section{Case study: vegetated gabion weirs (USA)}

With the proposed enlargement of an existing commercial site to accommodate a new supermarket in Exeter, New Hampshire, the drainage system needed to be redesigned [3]. Past attempts at stabilizing this stream have been done using riprap in steeper sections: during the initial design stages of the project it was noted that the riprap placed approximately eight years prior, was in failure and the stream was headcutting up through the riprap. The improvements are intended to help stabilize this portion of the existing stream channel and will also help to provide some flood storage and re-establish a more naturalized area throughout the site.

The solution selected to mitigate the erosion problem in the stream consists of the following improvements:

- Realigning the existing stream to help reduce the bank erosion by eliminating abrupt changes of direction.

- Flattening out the slope of the stream channel to reduce the tractive forces of the channel.

- Providing gabion / riprap energy dissipation structures that will provide controlled areas to change the channel elevation of the stream.

- Providing a low flow channel for small event $<1 \mathrm{yr}$ storm. The channel will range from 1.5 to $3 \mathrm{~m}$ wide depending on the section of the stream and the coir logs will be installed along the channel to help create a natural stream bank over time.

During construction of the weir, woody shrubs were inserted between the layers of trapezoidal gabion units.

\section{Material selection}

The material selected for the gabion facing was the Terramesh System, a facing with integrated PVC coated steel mesh as a reinforcing panel. The Terramesh was selected because of the connection by friction with the geogrid which is done by overlapping $3 \mathrm{~m}$ of mesh with the geogrid. The gabion facing of the unit could also be connected like standard gabions with all the adjacent units to form a monolithic structure. The gabion facing of the reinforcing units were modified to form a trapezoidal shape to allow vegetation to grow. Coconut fiber was placed on the facing of the trapezoidal shape units to keep top soil in place and enhance the vegetation to grow (Figure 5). 


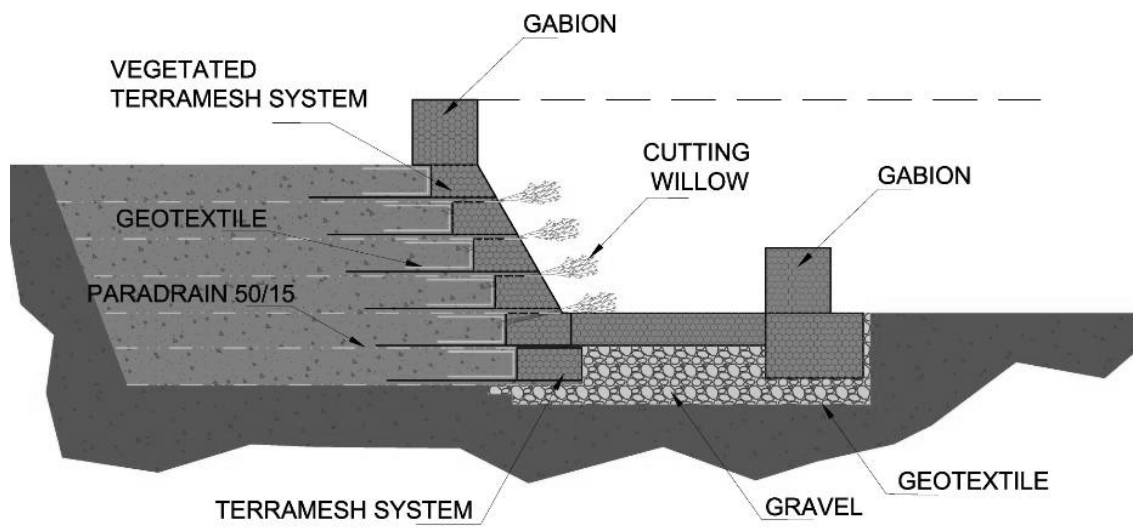

Figure 5: Cross-section of the vegetated weir.

Design stability analysis

The analysis was performed using the MACRA 2 program for the hydraulic calculation and MACSTARS for static stability. The hydraulic calculation provides information regarding the minimum length of the basin necessary to dissipate the energy from the drop structure and also the water level at different locations. The water levels information is used for erosion control protection design upstream and downstream of the weirs. For this project, the length of the dissipation basin calculated was $3 \mathrm{~m}$ minimum with a low flow section inserted in the weir and the counter weir. A thickness of $0.75 \mathrm{~m}$ of rock at the bottom of the stilling basin was necessary to dissipate the energy from the weir and to prevent scour. Both sides of the basin were protected from erosion using standard PVC gabions. The global, internal and sliding stability analysis of the weir were done considering a saturated soil and surcharge loads from the water above the weir.

Assembly and installation

Construction on the site began in late fall 2004 during the dormant season for the vegetation and was completed in early spring 2005.

First step, the site was excavated at the required level and length; any large debris that could damage the geogrid or the steel mesh during the compaction process was removed. The geogrid was cut at the required length and placed under the Terramesh units up to the facing.

Second step, the structural backfill was placed on the geogrid and the mesh and compacted with a light compacter. The connection between the Terramesh and the geogrid relies on friction. A geotextile was placed on the back of the facing units for separation to prevent the fine particles from migrating through the rock fill.

Third step, installation of the next row; the first two Terramesh rows were standard units without vegetation because they were installed below the low 
water level. The units were connected together with stainless steel fasteners to the lower and adjacent units to form a monolithic structure.

Fourth step, installation of the vegetation; the selection of vegetation was done considering their tolerance to being submerged for a long period of the year. The species must be a shrub type to allow growth within the gabion type structure. In the contract, the contractor had to select a mixture of species from the list with no more than $40 \%$ of the same species. 120 shrubs have been planted in the wetland area only. The upper units were modified to have a trapezoidal shape with an erosion control blanket secured inside the facing mesh to retain the top soil. Live stakes were placed between each row $15 \mathrm{~cm}$ apart (Figure 6).

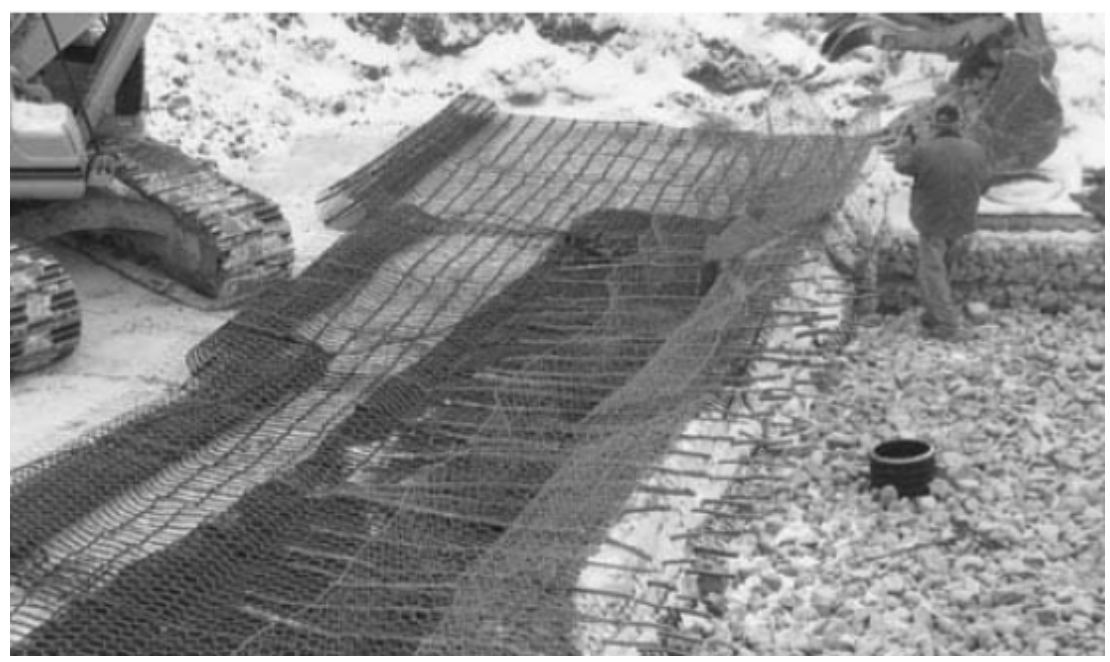

Figure 6: Shrubs inserted between the gabion layers.

The units were filled with rock first and top soil afterwards to fill up the voids between the rocks. The quantity of topsoil required represents 30 to $35 \%$ of the volume of the trapezoidal gabion unit. Top soil has two functions: one to provide a good medium for root enhancement, and second to keep a higher moisture level in the gabion facing. The live stakes were at least $1.2 \mathrm{~m}$ long to exceed the $1 \mathrm{~m}$ width gabion of the gabion facing. Irrigation of the vegetation was provided for the first year after the construction to provide a better success rate of survival. Next, the dissipation basin was constructed with all the gabions interconnected together at their edges and to the weir.

Final remarks

The weirs are presently working very well (Figure 7); the installation took longer than scheduled mainly because of the weather. After only one growing season, the vegetation was well established. The stability of the weir will increase as the root system is developing within the reinforced area. The structures have been subjected to numerous storms since installation, including a 100-year plus event. 
During that event, the upper two structures were totally submerged. After the storm had receded, an inspection of the structures and vegetation showed that the entire system had functioned as designed.
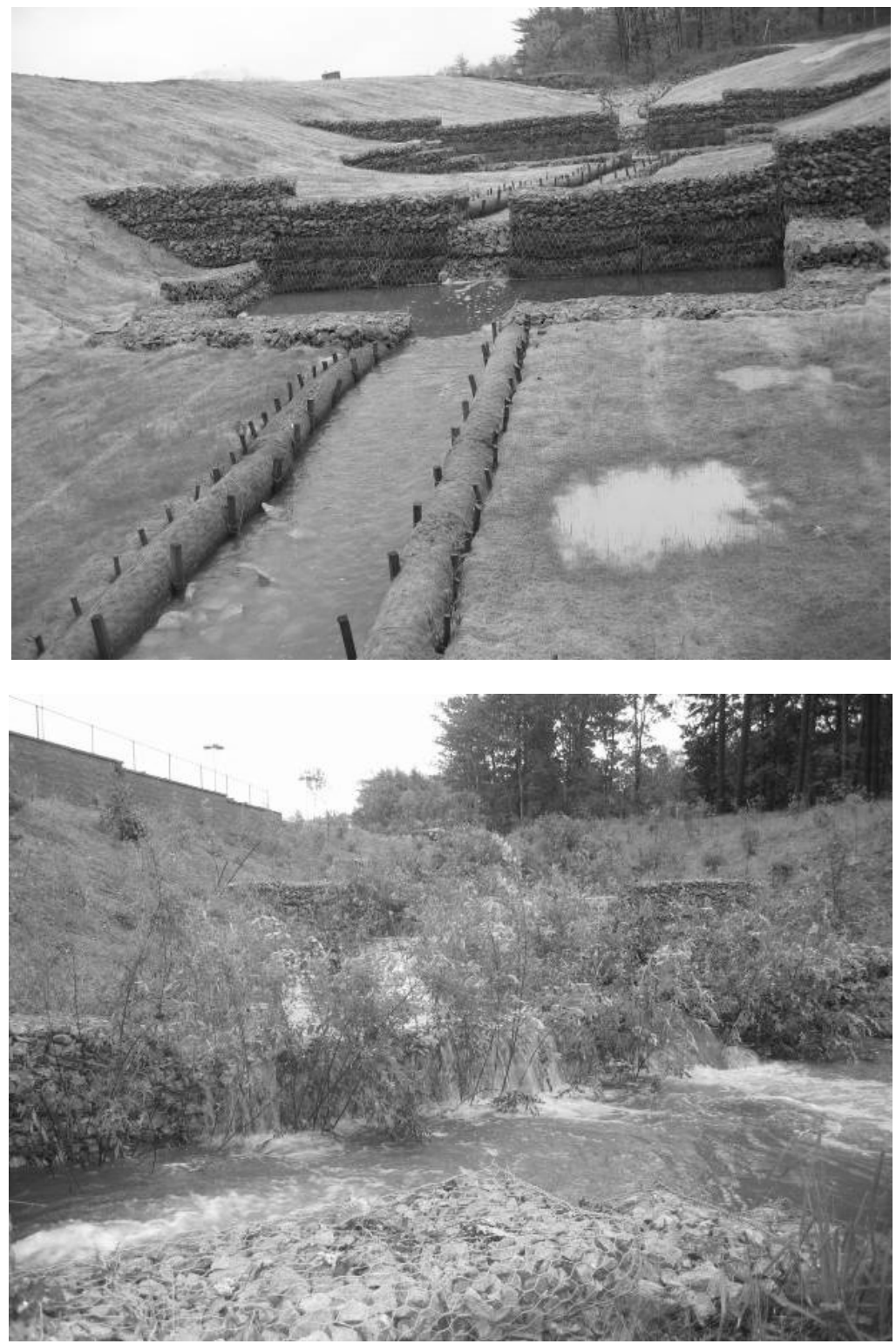

Figure 7: The weir after construction and after one growing season. 


\section{Case study: bank protection with green gabions (UK)}

A scour protection scheme was required to protect a collapsing section of the right-hand bank on the Severn river in Shrewsbury. Erosion had undermined the toe of the $2-3 \mathrm{~m}$ high, $60^{\circ}$ bank and the $70 \mathrm{~m}$ long section of river bank was progressively slumping into the river.

As a public right of way, a remedial scheme was prepared but neither the Environmental Agency nor Shropshire County Council Leisure Service Department, responsible for the County's Public Rights of Way network, favoured a sheet-pile solution which although in the term would be considerably more stable, would be subject to longer term deterioration and corrosion.

A soil bio-engineering solution was eventually adopted as it allowed retention of the existing tree growth along this section of the river and resulted in being more economical than the sheet-pile wall.

\section{Installation}

The Environment Agency and the County Council favoured a design forwarded by consultants, Land Conservation Associates and the work was carried out during October to November 1994 by K\&M Construction Ltd of Wellington, Shropshire.

A scour protection wall was constructed comprising live willow stakes and $1.2 \mathrm{~m}$ long PVC coated galvanised wire hexagonal woven wire mesh tubular gabions lined with the soil saving coir blanket. The tubular gabions were laid blockwork fashion in courses as a single skin following the $60^{\circ}$ slope of the bank. Willow cuttings $0.75-1 \mathrm{~m}$ long and $20 \mathrm{~mm}$ diameter were laid horizontally along the top of each course at $0.3 \mathrm{~m}$ intervals, each end driven into the bank to a depth of $150 \mathrm{~mm}$ with about $200 \mathrm{~mm}$ protruding beyond the tubular gabion (Figure 8).

Crushed stone fill was placed in the gabions laid at or below low summer flow level: these tubular gabions were $0.5 \mathrm{~m}$ diameter and lined internally with a biodegradable coir blanket to retain the fine aggregates.

For the remaining upper courses a $50 \%$ granular-50\% loam fill was used to fill $0.3 \mathrm{~m}$ tubular gabions. This enhanced the growth potential for volunteer vegetation on the face of the wall, which rose in a series of steps from 6 to 11 courses over a length of $70 \mathrm{~m}$ (Figure 9). Granular backfill was placed in any hollows behind the tubular gabions; fill materials were slid down the flight of steps from the nearest road in open chutes.

The cost of the bio-engineered solution was only one-third of the cost of the sheet-pile alternative and it was constructed by a small team even though the site was accessible only from the river or from a flight of steps: the lightweight and modular nature of this scheme was of great advantage. 

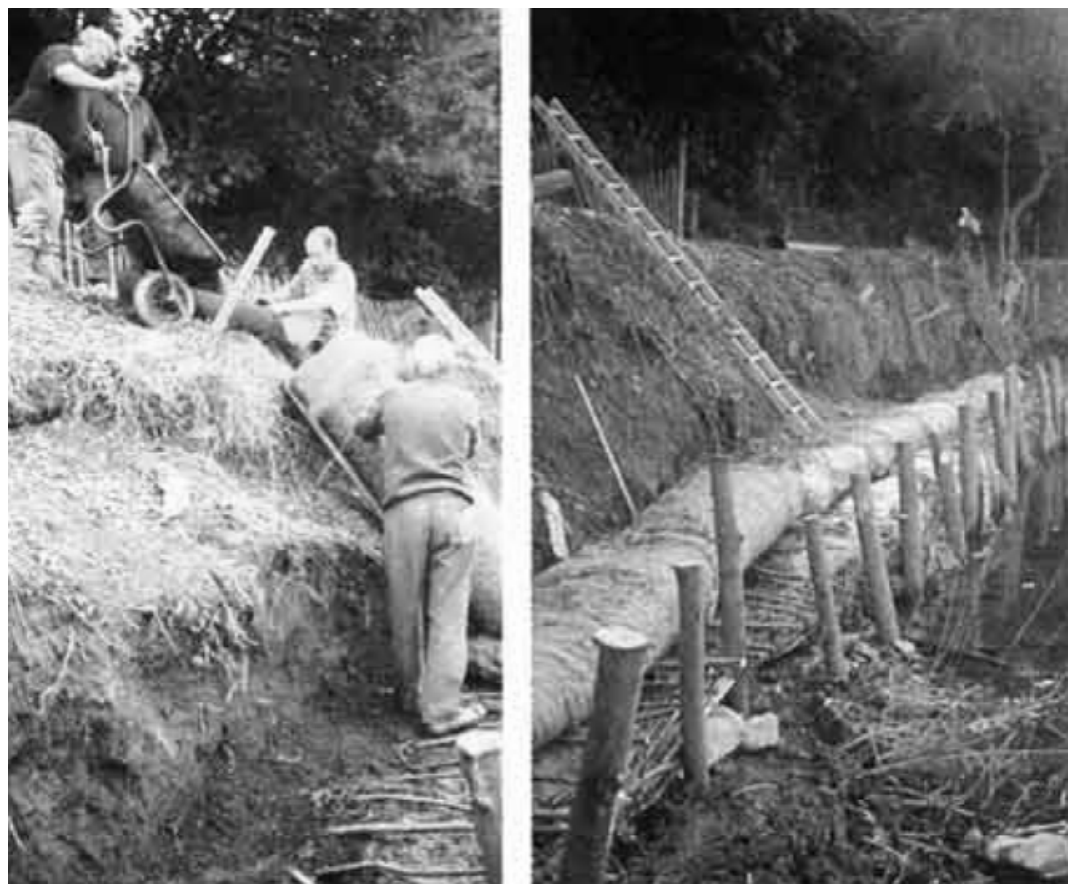

Figure 8: Filling and installation of the tubular gabion and willow cuttings.

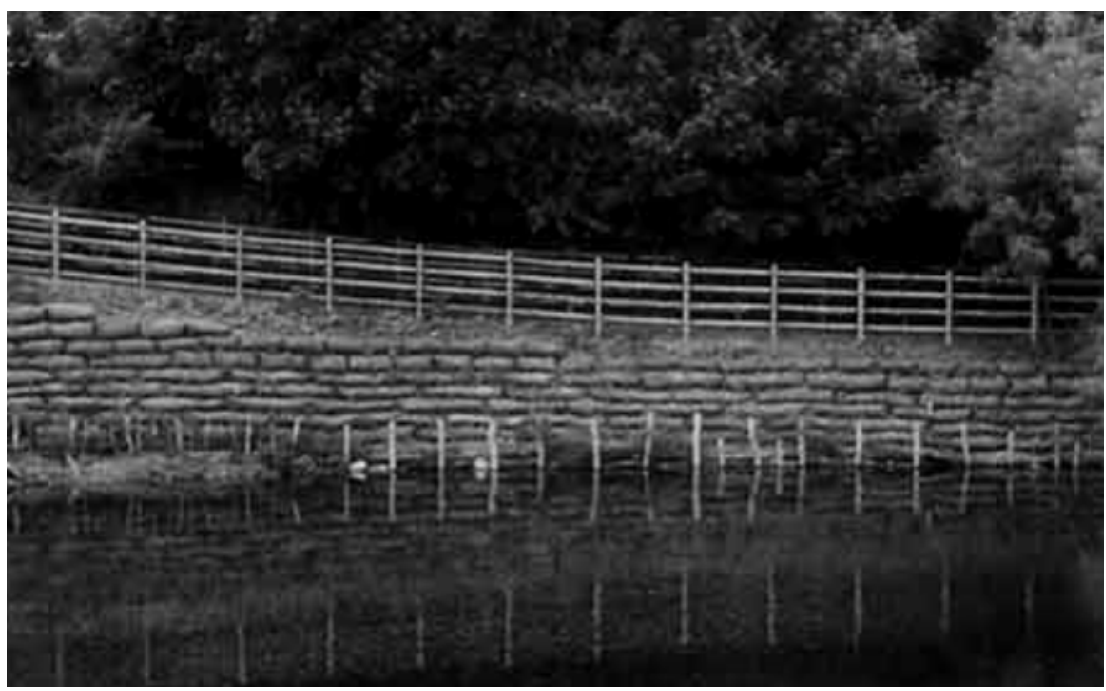

Table 1: $\quad$ The finished bank after construction (november 1994). 
Final remarks

The wall was subject to full-height flooding almost immediately after completion and for most of the following winter: the structure suffered no damage, allowing the living material to continue to establish.

The appearance after only a few summer months growth was already very attractive; the willow roots developed significantly penetrating the bank, adding to the long term stabilising effect. During this period of establishment the gabions provided the initial scour protection and themselves became naturally colonised with superficial growth.

The wall has gradually developed into a living flexible structure (Figure 10) providing habitats along the waterline for fish and for other life forms such as invertebrates and small mammals.

The vegetated wall needs little maintenance, comprising an initial 3-year after care period of low-cost annual pruning of stems each autumn; thereafter, coppicing on a 5-year cycle yielded optimum performance and further living material for additional bank protection works.

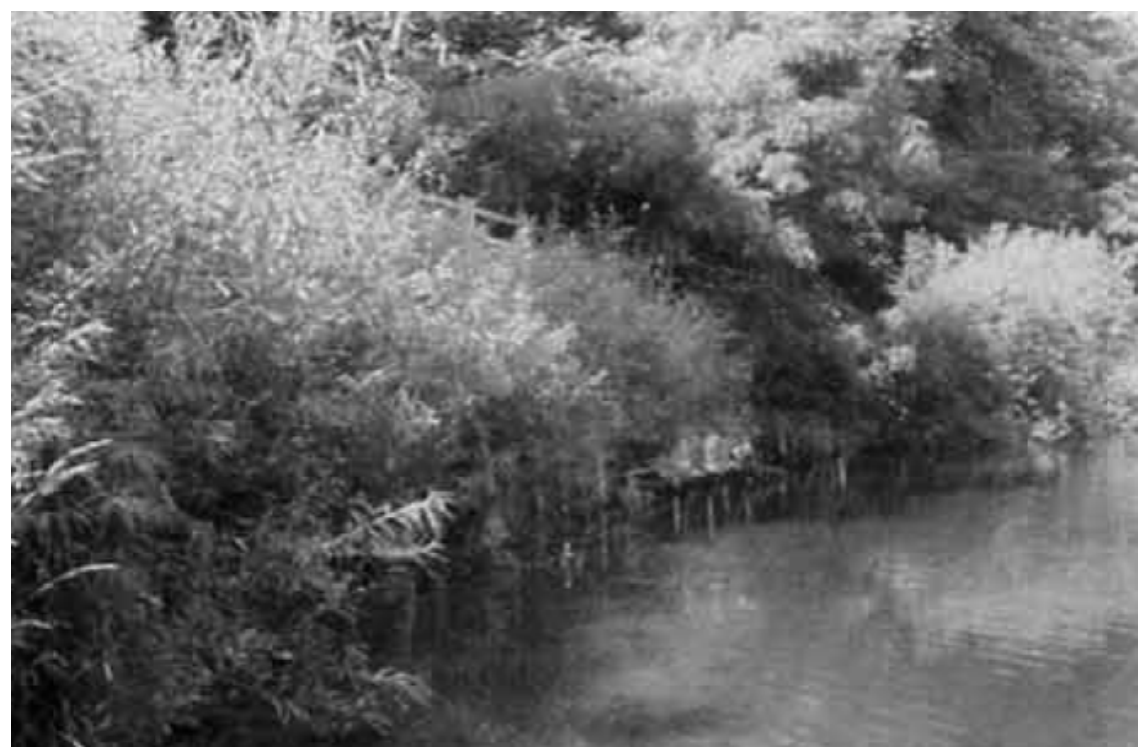

Table 2: $\quad$ The bank with established willows (july 1996).

\section{Conclusions}

Any kind of soil bio-engineering solution must be used only in relationship to its function, without introducing simplifications. Vegetation can ameliorate many of the factors and conditions causing earth slope and riverbank instability, but we cannot ask either the plants, or their roots, to provide something they will never be able to give us in the cause - effect - solution chronological scale. 
The successful applications of wire mesh products as inert material combined with plants to ultimately create a complex living block, have shown their suitability to restore natural ecosystems by providing, at the same time, the engineering functions required to guarantee that designed structures perform under safe and reliable conditions.

Furthermore, these solutions minimise the impacts on climate change, having a sensitively lower carbon footprint than equivalent traditional engineering solutions in terms of $\mathrm{CO}_{2}$ emissions.

\section{References}

[1] AIPIN (1997) Codice deontologico Associazione Italiana per l'Ingegneria Naturalistica.

[2] APMC (2012) Carbon Footprint dei Gabbioni e Materassi Maccaferrie confronto con soluzioni tradizionali (Unpublished).

[3] BRUNET G., SHUEY R., (2006) Stream stabilization with vegetated gabion weirs, Land and Water Volume 50, Number 5.

[4] BRUNET G., SHUEY R., (2005) Stream bank stabilization with vegetated gabions, Land and Water Volume 49, Number 1.

[5] GOLDSMITH W., (1976). Soil Reinforcement by River Plants: Progress Results. 